\title{
Events Tourism: A Potential to Build a Tourist Destination Branding: the Case of Cultural Events in Egypt

\author{
Dalia Amara
}

College of Management and Technology, Arab Academy for Science and Technology and Maritime Transport

\begin{abstract}
Cultural events of different types are part of the attraction of a destination and have become an increasingly significant component of destination branding. Many destinations throughout the world have developed events portfolios as a strategic initiative to attract tourists and to reinforce their brand. This implies the need to evaluate the contribution of an event not just in terms of the direct financial contribution that it generates but also in terms of its consistency with the destination brand values. The study aims to analyze and interpret the expectations and the potential impact of cultural events on destination branding, highlighting the importance of achieving a good 'nation brand', which became a valuable asset for any tourist destination. The paper suggested that cultural events are the key tourism marketing tool and that they present an opportunity for destinations marketers to help position their destination amongst its competitors. A field survey based on qualitative approach was conducted through interviews with the industry key stakeholders, in addition to the observational descriptive research, investigating the interaction of both cultural events and destination branding attributes on tourists' intention to visit the destination. The study introduces the contribution and the effects of selected examples of 'cultural events'; El-Moez street festival and Abu Simbel Sun festival. These events were selected according to latest tourist online reviews, which are so identified with the spirit or ethos of the place or the destination, gaining widespread recognition, enhancing awareness, and thus having a potential to be particularly effective in promoting, regenerating and branding Egypt as a tourist destination.
\end{abstract}

Keywords: cultural events, tourist destination, destination branding, Egypt.

\section{Introduction}

Today, events are central to our culture as perhaps never before. Increases in leisure time and discretionary spending have led to a proliferation of public events, celebrations and entertainment. Governments now support and promote events as part of their strategies for economic development, nation building and destination marketing (Glenn.A.J.Bowdin et al., 2011). Events are part of the attraction of a destination and as such should be included in the integrated marketing for the destination and incorporated into a destination's branding strategy. This suggests and mandate a reconciliation and frequent redefinition, reevaluation of events and its social, economic, political direct and indirect impact, both on long and short term. During the last two decades, the number of sports and cultural events designed to attract tourists to every corner of the globe has multiplied many times (Williams and Bowdin, 2007; Jackson, 2008). More recently, the growth of events became a worldwide phenomenon. Cities and towns have added major events with increasing recognition of the role that events can play beyond merely entertainment, linking in to cultural, arts, regeneration, education, tourism and other strategies. These events include exhibitions, crafts expos, themed markets, festivals, and fairs to their traditional offerings (monuments, museums, mountains). The UK is widely recognized as a leader in the events field, for example, with successful events such as the Edinburgh International Festival, the 2002 Manchester Commonwealth Games. Liverpool successfully hosted the European Capital of Culture 2008. This prompted a series of events before, during and after 2008 and significant investment in cultural infrastructure, revitalizing the city (Garcia, Melville and Cox, 2010). The increasing interest in events in Asia was reflected in the 
establishment of the International Festivals and Events Association affiliated in Beijing, Singapore and South Africa in 2006. In Australia, the state governments' events corporations and the staging of the Sydney Olympics, the Rugby World Cup and the Melbourne Commonwealth Games are regarded as international benchmarks for best practice in the field.

\section{Research Aim}

The study aims to analyze and interpret the expectations and the potential impact of cultural events on destination branding, from the perspective of the tourism industry stakeholders, highlighting the importance of achieving a good 'nation brand', which became a valuable asset for any tourist destination. It represents the ability of the destination to continue to trade at a healthy margin for as long as its brand image stays intact. The study stresses that understanding, measuring, and even managing successful events, is one of the primary tasks of responsible public stakeholders, helping in enhancing or maintain a destination positive image.

\section{Culture and Events}

Culture authenticity has been widely discussed in the tourism literature and over the years' authors in the tourism field have provided studies of culture, being attached to artefacts, tourism activities and events. In ancient Rome, the term culture referred to the shaping of the human mind (soul) through contact with various fields of philosophy and arts allowing a person to achieve spiritual balance and harmony with the universe (Corneanu, 2011).As the twentieth century and twenty-first century have been a period of intensive globalization, international migrations and clashing of the cultural patterns of various societies, more significance was being attached to the roles of culture in social life (Cudny,W.2016).Culture became a valuable economic component, used for the socioeconomic stimulation of regions also those in crisis. It was included in the marketing strategies of countries, regions and cities and used for their economic development, promotion and creation of a positive image. There appeared numerous culture-based products, which play an increasing role in the local, national and global economy, referred to as the cultural economy of cities (Scott,A.J. 2010). Therefore, the development and the growing importance of culture are followed by the increasing role of events, especially festivals, started to be treated as a product, which brings material and promotional benefits in the contemporary world (Hawkins, H.2013). There are many different types of cultural events, classified according to their theme, scale, the way they are organized, etc. Local culture and identity shape and give definite meanings to some places and to the urban space as a whole (Madden, 2012). Thus, the place authenticity and the historic value of its built environment carry and promote culture. The linking element between a destination and its culture increases opportunities to accommodate cultural activities including events, which are a main purpose for gathering and attracting, people and consequently branding the destination. Many cultural events are, in fact, adopting the ancient rituals and traditional forms created by destination managers in order to improve the development of tourism in that region (McCartney and Osti, 2007). As cultural events are leading destinations to replicate successful themed events, motivating more and more the destinations to introduce their own histories and cultures in order to brand their own distinct and indigenous tourism attractions. It is important that cultural events are to be considered by the destination's local community, as tourists consider them. The degree, to which a cultural event is staged for tourists and sustains its heritage legacy as perceived by visitors, can have an impact on tourism satisfaction and the income it generates. 


\section{Event Tourism and Destination Branding}

Due to the fierce competition in the international tourist market and the increasing number of destinations developing a variety of quality tourist offers, the notion of branding has started to expand among destination marketing organizations (DMOs) and became apparent as a topic of examination (Wagner\& Peters, 2009). In order to be successfully promoted in the targeted markets, a destination must be favorably differentiated from its competitors, or positively positioned, in the minds of the consumers and potential visitors. A key component of this positioning process is the creation, management and communication of a distinctive and appealing perception, or image of the destination (Echtner and Ritchie, 2003). Hence, the use of branding is by some, considered to be the most powerful tool available to develop tourism destinations (Morgan, Pritchard and Pride, 2011). Destination branding is focused on lowering costs, changing the type of visitors, changing the nature or behavior of visitors, but also changing tourism products, integrating stakeholders and communities, avoiding irritations and responding to issues, for instance, created by the present economic crisis, and challenges at the digital level. An understanding of the critical issues involved in the branding and management process of destinations is an essential element to secure the success of the tourism industry (Fyall, Wang and Garrod, 2012). Successful destination branding strategies in the globalized and 'networked' world relies on a collaborative approach among destinations stakeholders (i.e. public and private sector) and harnessing the power of the online contents, "the community, and like-minded brands where the overall effect is greater than the sum of the individual parts"' (Munro and Richards, 2011).

Events can be used for brand marketing and more differentiated marketing efforts, directed to specific target groups or particular segments of the market. The destination can be seen as a 'brand with a broad supply of urban products'. Image and identity are important location factors, but cannot by themselves change the general perception of a city or region. Major planned events can be focal points of brand-marketing strategies. In building a brand for a destination, it has been argued that the identity creation should not be restricted to the visual but should create an emotional relationship between the destination and the potential visitors (Morgan et al., 2011). This could be achieved by holding planned events that encourage and attract visitors to the destination. There has been a notable growth both in the use of, and in demand for, cultural events for tourism development as tourists search for authentic and distinctive experiences. With this growth, Egypt having such a rich history and cultural assets is no exception, promoting its image, profile and destination brand, and this was the major focus on this research by targeting the market looking for cultural experiences.

\section{Cultural Events' Impacts on Host Destination}

The tourism industry supporting events generates employment and economic diversification. Through cultural events, places may attract not only tourists but also investments. Events carry positive impacts in three parallel areas; attracting tourism, improving the place's image, while supporting the local community. While the destination is always available, having a time-limited event encourage visitors to take advantage of this opportunity and visit the place during the event. For example, although many people are interested in visiting Brazil, the famous carnival in Rio de Janeiro creates a feeling of unique chance, pushing potential visitors to take full advantage of the activities. During events, visitors have a unique chance to interact with the local community, gaining a deeper experience of the ambience, customs and local culture. Along with tourists, events attract journalists and other opinion leaders. For these audiences, events are a 'media event', which are expending the place's image and creating a window for positive media 
coverage. At the time of events, it is easier for destinations to demonstrate their positive facets, focusing the media's attention on favorable occurrences. For the destination's local residents, events are a unique occasion to celebrate the local culture and interact within the community. For the residents of Munich, for example, the Oktoberfest is a long standing tradition where they can meet their friends, take pride in the Bavarian culture and enjoy local dishes (Avraham, E \& Ketter,E, 2010). In the tourism context, festivals can boost the local community in two major ways. First, people of the local culture are being flattered by the international interest in their culture. This enhances the residents' pride and promotes the preservation and cultivation of the local culture. Second, the tourists and visitors are spending money within the community, enhancing the local economy and supporting restaurants, hotels and other tourism -related businesses.

A societal marketing approach (Kotler et al., 2008), emphasizes the importance of society's well-being alongside satisfaction of the needs and wants of event or festival markets. The value of events is ameliorating the image of municipalities and in attracting tourists. Events make it possible to maximize and rationalize the use of certain spaces. Preservation of these spaces may result in financial benefits and dissemination of artistic and cultural heritages. Events can function as attractions that motivate both local and nonlocal travel and may increase tourism spending and length of stay. It may also assist in keeping residents and their money at the home destination, rather than travelling somewhere else. Events can furthermore act as animators by structuring programs of special events at already existing facilities in order to make extra use of theme parks, museums and resorts. This has the advantage of attracting people who may otherwise not visit the premises and can as well encourage people to make repeat visits. Major events may act as image-makers through its role of forming the image of a destination, much due to the media attention and publicity it attracts in relation to the event. Before efforts and investments are made to develop these events, it is necessary to assess the impact they may have. These assessments are crucial to the planning process (Williams and Bowdin, 2007).

\section{Case studies of Cultural Events in Egypt}

Egypt exerts every effort possible to diversify its modes of tourism and to introduce new types of tourism that cater to the taste of the various tourists. Cultural events, including festivals, are a universal form of events that pre-date the contemporary events industry and exist in most times and most societies. Increasingly linked with tourism, they have a great importance in generating business activity and income for host communities. Meanwhile, local authorities and government/regional agencies are taking initiatives one stage further, by developing what so called 'event-focused strategy'.

In a research of an exploratory and descriptive character, case studies are considered a good method of making a statement when answers are required to questions such as "how" and "why", the researcher has select two 'hallmark cultural events' having a potential to promote, regenerate and branding Egypt as a tourist destination. The following two case studies were selected according to latest tourist reviews Abu Simbel Sun Festival trips score an average of 4.57 out of 5 based on year 2017 reviews (http://www.intrepidtravel.com/us/egypt/egypt-experience-abu-simbel-sun-festival-

101823). As for Al- Moez Street Festival, recognized as one of the oldest streets in Cairo, several government renovations have managed to improve and transform the street into an 'open-air' museum of sorts. These renovations had a sounded effect at the local as well as the international level, especially at the social media attracting visitors to attend all cultural events held at this historical street. 


\section{Al-Moez Street Festival}

El-Moez Street is one of the oldest and amazing streets in Islamic Cairo. It dates back to the Fatimid dynasty. The street got its name from the 4th caliph in the Fatimid dynasty. It stretches from Bab Al-Futuh and Al-Hakim Mosque to the in the North to Bab Zuweila, one of the three remaining gates of Old Cairo, South of Cairo. The street spans approximately one kilometer. El-Moez Street has the greatest concentration of medieval architectural treasures in the Islamic world. The artist, Nasr El-Fattah, the president of the Dialogue Foundation for the arts of people's cultures, has announced the start of "The Carnival of the People", from the International Festival of Drums and Arts, at Al-Moez Street, with the participation of more than thirty bands introducing different cultures. The idea of this national event project started in 2008 then again in 2011. The project was submitted to all ministers concerned; the Ministry of Culture, which sponsors the Festival of Drums and Heritage Arts, through the Cultural Development Fund Sector and the Foreign Cultural Relations Sector, in cooperation with the Ministry of Planning and then the Ministry of Tourism. Expert working groups from the Ministry of Planning and Antiquities start by a monitoring phase for the Great Street or in other words the attraction site, followed by the work of an integrated vision supported by illustrations for this cultural national project. The project's objective is to transform Al-Moez Street into a market and an international forum for heritage based on the revival of the historic arts of Cairo and the commemoration of the popular processions and processions. Celebrations of the New Year and celebrations of Coptic events, and others with a new artistic vision highlighting the uniqueness of the architecture and genius of the greater street, which interact with the cultural and cultural inventory of the people of Egypt. The project aims at linking Al-Moez Street with the historical cities of different cultures around the world. This Street embraces the heritage of ancient cities around the world through international celebrations throughout the year, and encourages the construction of historic hotels, with a plan to prepare cultural and tourism programs to market historic Cairo as an integrated destination for cultural and historical tourism. On April 21, 2017, this event dream was achieved by embracing the National Commission for the Development and Protection of Historic Cairo under the leadership of Eng. Ibrahim Mahlab, the Assistant President of the Republic for national and strategic projects, to inaugurate this major national project. http://www.cdf.gov.eg (June 2017).

\section{The World-famous Abu Simbel Sun Festival}

Temples of Abu Simbel is the sole reason for which tourists from all over get attracted to this part of Egypt. Built by King Ramses II, the temples of Abu Simbel are touted to be the most impressive one. The Sun temple, located on the banks of River Nile, was built in $1250 \mathrm{BC}$ and is carved into the sandstone cliffs. The seated Ramses statue of 65 feet is the temple's main attraction. There are two temples, one of Ramses and second for his queen Nefertiti. The extraordinary beauty and grandeur of the temple is simply spell bounding. The temple remained hidden from the world until 1812, when the Swiss explorer Johann Burckhardt found it. In 1964, the temple was conserved to protect from the rising waters of the High Dam of Aswan. The entire site was dismantled and moved to a place $65 \mathrm{~m}$ higher and $200 \mathrm{~m}$ back of the river, where the structure was reassembled again. The monument is a memory of Ramses II's victory in the Battle of Kadesh and it took about twenty years to get built. The Sun Festival at Abu Simbel Temple, which remains in darkness all through the year, sees the stream of natural sunlight only on two occasions every year, which are on February 22nd, the anniversary of Ramses' ascension to the throne and on October 22nd, which is his birthday. The light, which streams into the complex, reflects on Ramses II and Sun God has seated statues, illuminating the entire place highlighting the brilliant 
architecture of the place. The statue that remains in darkness, even on these two days is of Ptah, the Goddess of darkness. The sight is truly a marvelous one and attracts tourists from all across to celebrate the much-celebrated Sun Festival. The festival is based on a solar phenomenon, and the Sun God being a historic symbol to Egyptians (http://www.egypt.travel/attractions/sun-festival-at-abu-simbel-2/ETA).

Over 4,000 tourists were gathered at the 3,200-year-old Egyptian temple of King Ramses II, to watch the sun illuminating the statues, to witness solar-alignment on the king's face and to meditate. Tourists from different countries including Japan, China and Germany enjoy the spectacular solar phenomenon while admiring the statutes, considering the knowledge of astronomy that ancient Egyptians used for making such construction (Egypt Independent, February 22, 2016). They also participate in other cultural activities, including dancing and singing during local folkloric shows, tasting local cuisine platters, and /or buying local souvenirs. The festival is a mixture experience of cultural awareness and fun-filled event for its targeted market. The Egyptian authorities attempt to revive the country's image, which suffered greatly in the wake of the 2011 uprising and the political turmoil and violence that followed. With great concern, the Ministry of Tourism gives special attention and efforts for the planning and the organization of this event, including the coordination of the event with physical and communicational infrastructure of the place ensuring all event's arrangements are accomplished according to the settled plan with great concern to security measures taken in coordination with military control, in addition to accommodation arrangements, as the occupancy rate reaches $70 \%$ in October and February at the time of these occasions every year, according to Egypt Independent (December 14,2016).

\section{Research Methodology}

This explanatory study followed a qualitative research method which was conducted through In-depth interviews with key stakeholders; the local responsible working in public Egyptian tourism and cultural authorities, including the Egyptian tourism authority (ETA), the ministry of Culture, which sponsors cultural events, through the Cultural Development Fund Sector and the Foreign Cultural Relations Sector, in addition to the General Authority for Culture Palaces. Observational descriptive research, and content analysis of communication materials, were used to identify how far Egyptian tourism authorities give considerable concern to event tourism concept generally, and cultural events specifically. Moreover, how far, they consider the brand in their tourism marketing strategy as a key source of competitive advantage. It is within the context of the interviews, that the researcher investigated the interaction of both cultural events and destination branding attributes on tourists' intention to visit the destination, as one of the main tourism marketing tools for the destination. The questions followed an interview guide format, with appropriate probes used to encourage an informal conversation.

The choice to start with a qualitative research is to develop a set of concepts that help in understanding this social phenomenon in natural setting rather than experimental due emphasis on the meanings of the pragmatic experiences survived and the view of participants who frequented such cultural events. The researcher lead herself to believe that empirical evidence gathered is related to both theoretical ideas and structures that lies beneath observable reality. Although such data partially reflect what goes on when planning for a cultural event; the research's data was used to make successful generalizations and conclusions as it includes in-depth explanatory data from a small sample; enough consideration is taken to use both the deductive and inductive approach in data analysis. 
As for the observational research, it was conducted by the researcher who attended Three of the most important cultural events held annually in Egypt, at different time of the year, which are the Festival of Drums and Heritage Arts held at Al-Moez street and sponsored by the Ministry of Culture, Cairo's Sphinx Festival, held at the Swiss club, it is a gathering of international artists, scholars and Egyptologists. It celebrates the fusion of art and science with music performances and dancing shows and seminars on topics related to Egyptian cosmology. And the third event was the Caravan arts festival, gathering around 40 leading Middle Eastern and Western artists at St. John's Church in Cairo, encouraging intercultural dialogue through art exhibitions, film screenings and concerts.

\section{Data collection and Content Analysis}

The observer received a detailed explanation of each event evaluation variables. In addition, how each variable is operationalized during the event? Qualitative observations were recorded. The researcher performed a "walk-through" of the research aim and observation process prior to attending the selected events, to ensure events' managers understanding and consistent implementation of the data collection. Observation and listening were usually sufficient to gather information about each variable. For example, for the target market, the researcher checked tourism buses arriving at the parking lot of each event venue, to see incoming tourists' groups as well as locals arriving by their private cars to attend and/or participate at the selected events. She could tell what languages were spoken by events' participants. She could ascertain if they were repeat participants if they appeared familiar with the event venue/location at their arrival. However, when some variables were difficult to observe, the researcher was having the chance for asking questions to events' managers. The researcher visited each event's venue, according to their time scheduled, and spends 4-5 hours in each location to record detailed notes of how each event management variable was implemented, as well as on site event planning and marketing variables.

Content analysis was employed to examine the nature and level of communication of cultural events planning and arrangements by tourism local authorities. Content analysis uses an objective, systematic approach to measure the meaning of communicated material through the classification and evaluation of selected words, themes or concepts. The goal of content analysis is "to provide knowledge and understanding of the phenomenon under study. The methodology of content analysis has been developing since the early 1920s in such areas of scientific inquiry as political science, psychology, and communications; it was also adopted in tourism research, though to a lesser extent (Stepchenkova et al, 2009). There are two methods for content analysis in social sciences: qualitative and quantitative. The qualitative method used in this study, refers to non-statistical and exploratory methods, which involve inductive reasoning. Content analysis as a method of gathering information requires correct codifying of qualitative information into predefined categories in order to derive patterns in the analysis and reporting of information (Thia and Ross, 2011).

Foremost research, content analysis provides a replicable methodology to access deep individual or collective structures such as values, intentions, attitudes and cognitions. Among the key strengths of this method noted are the flexibility of the method can be applied to examine any written documents, as well as pictures, videos, and situations, can help decipher trends in groups or individuals, inexpensive, establishing reliability is easy and straightforward and of all the research methods, content analysis scores highest with regard to ease of replication. Usually the materials can be made available for others to use (Vitouladiti, O.2014). All types of communication materials were analyzed including brochures, fliers, Web pages, and videos. Interviews with tourism and cultural events 
responsible and travel operators provided further insights into the level of communication given to tourists both before and during the event. The researcher approaches the text by making notes of her first impressions, thoughts, and initial analysis. As this process continues, labels for codes emerge that are reflective of more than one key thought. These often come directly from the text and are then become the initial coding scheme. Codes then are sorted into categories based on how different codes are related and linked. These emergent categories are to organize and group codes into meaningful clusters (Patton, $\mathrm{M}$. 2015). The purpose of this step was to facilitate subsequent analysis by identifying all of the text associated with a particular elicitation or a specific question.

\section{Results and discussion}

Through the interviews, it was realized the importance of the roles of such events in the offer and in the process of tourist destination branding, and that event marketers, as well as tourism stakeholders, are increasingly aware that especially cultural events are desirable to the host destination to the degree that it can enhance the destination's brand. Discussing the factors that affect positively the success of the research's studied events, results include the coordination of events with arts, cultural and traditional values of Egypt, pride of local population and their support to such events. In addition to, the cooperative work of all the responsible authorities and participants in the events' creation and implementation, event media coverage which is still a point of weakness, need more concern and planning and last but not least the inclusion of the country's name in the event title, logo and /or slogan.

After analyzing the recorded observations, findings revealed that although there are similarities in event organization procedures, venue or location management, and promotion strategies; the Drums and Heritage Arts festival appear to have better marketing strategies with respect to performed shows, venue atmosphere and service provided than the other two events. All the three studied events have low scale media coverage; although some print advertising and trade /cultural publication, advertising is common in all three events. Advertising appeals appear slightly more effective for Cairo's Sphinx Festival. However, broadcast advertising, personal selling and special promotions are not commonly used. Internet advertising is efficiently used for the Drums and Heritage Arts festival. These events schedule may be printed in a tourism guide, available in all tourism information centers and tourism website, outdoor signage on the roads. As one would expect broadcast media are expensive and less likely to reach the target audience. Among various cultural local events organized at different time of the year in Egypt, interviews responses all agreed that only the Opera Aida concert at the Cairo Opera House and the Sun Festival previously described are the only two cultural events that have high scale media coverage, and very strong concern to attract potential number of visitors and which are assigned within the country's marketing strategy, and therefore sound internationally. Results revealed that a destination's rating raises when paired with events. According to the head of the regional tourism and promotion Authority, events can act as tourist catalysts and can provide the destination with the opportunity to overcome seasonality problems by offsetting periods of low leisure travel activity, increasing the number of tourists, their length of stay and expenditure.

The results of the study suggest that, yet events responsible in Egypt are not proactive in marketing and branding issues especially at the international level. They do not have specific marketing strategy to be applied to brand such events and a targeting budget for each type of cultural event that stimulates the tourism activity in connection with other activities to create a unique touristic environment that sound globally. Moreover, the creation of new cultural events similarly to other countries like in Spain and Morocco which grasp high revenues from such events or the Brazilian sets which attract millions of 
tourists to its streets. Then non awareness response during the interviews casted a serious and negative feedback upon the ability and capacity to dwell deep in promoting these culture even at the local and national levels.

Most of the travel companies and tour operators become more interested to tailor their packages, focusing on involving culture events held during their programs, being a core value of the trip program and therefore shaping the brand identity. Most of the tour operators interviewed agreed that more than $75 \%$ of their inbound tourists, are not travelling specifically to attend these cultural events, but they only grasp the opportunity to attend or to participate as part of their trip program or even it comes by chance unexpectedly to be confronted with a cultural event. Lack of complete information system on cultural events appears to be challenging dragging back the efforts of tourism actors.

Conscious of the fact that if the responsible authorities give more concern and efforts in promoting such important cultural events, taking into consideration examples of events organization best practices around the world, resulting in increasing tourists' arrivals and therefore tourists' revenue and employment rate, especially in developing countries such as the case of Egypt. This would be with no doubt a key to a successful destination-event co-branding strategy, added the representative of the Egyptian tourism authority (ETA).

According to the representative of the General Authority for Culture Palaces; "the challenge for events managers and organizers in Egypt, is to consistently fit the various forms of events especially; cultural events into the interrelationships among the elements of the marketing mix and therefore enhancing the destination brand equity". Thus it becomes significant that challenges exist and the society itself becomes one of the integrated in the marketing mix; accepting such type of events, festivals in streets, squares and other places in the Capital and country's big cities, or along the river Nile, in addition to locals' behavior towards tourists are keys to success for cultural events set in both dimensions' time and space.

Interviews' participants claim that certainly, events contribute to potential visitors' awareness of the destination. For example, a city staging a mega event such as the World Cup or the Olympic Games; can expect much media coverage and publicity and thus resulting awareness. Minor or in other words smaller scale events may not lead to such worldwide awareness but at least a properly targeted cultural event can yield strong regional and national benefits for the hosting destination. Most of the respondents' opinions were stressing that events act as an advertising strategy for the destination and contributes to create or maintain awareness of the destination.

An argument was that events and destination image transferred can be affected on political grounds related to the destination. Egypt's economy has been struggling since an uprising in 2011 ushered in political instability that drove away tourists. According to CAPMAS's statistics (April, 2017), the tourism sector received a severe blow following the downing of a Russian passenger plane in Sinai in October 2015, which killed 224 people on board. A plan was set by the Cabinet in May 2016 to improve the destinations' perceived image, and aiming to attract 10 million tourists to Egypt by the end of 2017. Respondents assured that events may strongly help tourism managers not only to change a destination negative image but also to contribute to its brand equity. Cultural events are thus can act as an indirect marketing tool to regain the international image; this is a real test of radical change that drove us out of a severe negative impact and moments of troubles tracing Egypt's history where creativity and innovation of the tourism sector becomes consistently of strategic importance. 


\section{Implications and Recommendations}

- Developing and promoting a high quality, inclusive program of public cultural events to raise the profile of Egypt as a tourist destination is of great importance.

- New attractive culture events' ideas should be adopted, to broaden the cultural horizon of the country and positioning it amongst the most creative worldwide destinations supporting the concept of "education, culture, outdoor art... etc."

- The more involved the host population in such cultural events as well as local suppliers in terms of provisions of services and attractions, the greater the potential to promote and to create a brand to their country. In this sense, the organizers must plan ways to build partnerships and involve the greatest possible local operators.

- Great emphasis should be attached to the principle of sustainable 'destination branding', given the growing importance of mega cultural events. These should not only focus attention on the host country or host city in the short term - there must also be recognizable long-term benefits, therefore guidelines toward the sustainable management and operation of such events should be announced and monitored intensively.

- Partnerships between public and private cultural institutions in tailoring an annual cultural events agenda could help greatly branding Egypt as a 'cultural center', attracting the international market all over the year and not specifically through a summer or winter season.

- Built attractions and facilities everywhere have realized the advantages of 'animation'the process of programming interpretive features such as the 'sound and light 'show, that make the place come alive with sensory stimulation and appealing atmosphere. This could be transferred to an annual event such as the idea proposed to Dr Khaled el Anani the Minister of Antiquities to plan for an international carnival theming the ancient story of 'Arous el Nile', 'the Nile Bride'.

- Moving back the great Verdi's Opera Aida, the most popular event and operatic work performed in Egypt, to Hatshepsut's Temple in Luxor, one of the country's most popular tourists' sites, as the Temple enhanced the event's visitors' experience coming from all over the world. The annual performances of Aida were moved in 1988 from Luxor, to a temporary theatre built at the old Giza Pyramids plateau, for about 16 years. Further performances took place at the Cairo Opera House, where it remains until date it has almost now become one of the pioneer international annual events, attracting the attention to Egypt as an appropriate destination for a variety of planned events, and a brand of Egypt's cultural tourism development. This may also help in encouraging back charter trips from all over Europe to many cities in Egypt, such as Luxor, Hurghada, Sharm El Sheikh...etc.

\section{Limitations and Further Research Proposals}

The study's survey was limited to only 'cultural events' used as a tool to build destination branding, also the interviews were conducted limited to public sector Egyptian tourism authorities, and tour operators. The unavailability and the inaccuracy of some specialized statistics was itself a weakness and limitation of the research that create a challenge not only for academics but for decision makers as well. The paper was far to tackle the relation of the available infrastructure to cultural events which mandatory to be taken into account to the success of festivals which give the feeling of freedom to tourists and the level of security monitoring in all places; streets, squares, avenues, and the regular control of such exogenous variables. Further research may include; the study of the conflict generated by the different interests and the diverging objectives of tourism stakeholders concerning tourism events promotion. Also, evaluating the impact of the media coverage and publicity of events carries a great part of destination brand equity. How Egypt tourism authorities 
can develop events portfolios as a strategic initiative to host 'mega event' representing a window for a society and its businesses. Hence, opportunities for future research remain open.

\section{Conclusion}

In conclusion, despite of the study's limitations, its findings provide important insights into the notable growth in demand for the different types of cultural events, as tourists always seek authentic and distinctive experiences. Egypt, having such a rich cultural resource-base, can use this variety of cultural events for its destinations' branding. As by their specificity, they have the ability to relate to the experiential needs of a target market. They can be developed to create emotions and to offer memorable experience that is uniquely associated with the destination and consequently with its positive image. The argument lies in the importance and impacts of events for tourism destinations. The use of events, when well-articulated with a destination branding strategy, could be a driving force to improve their strategic positioning and competitiveness, and to optimize the benefits they derive from tourism. Making strategies in destination branding requires the right people, the right mindset, the right internal structures, and the right stakeholder and industry relationships where, across all of those things, innovation, decentralization, and collaboration/networks are all important (Morrison, 2013). Finally, the study may have significant implications for tourism researchers, public tourism authorities, and events practitioners as well.

\section{References}

Avraham, E \& Ketter,E,( 2010) The Role of Festivals and Cultural Events in the Tourism Industry, in ' Media Strategies for Marketing places in crisis', Butterworth Heinemann

Corneanu,S. (2011) Regimens of the Mind: Boyle,Locke, and the Early Modern Cultura Animi Tradition. Chicago: University of Chicago Press.

Cudny, W. (2016) Festivalisation of Urban Spaces. Factors, Processes and Effects.Springer International Publishing, Switzerland.

Echtner,C.M. and Ritchie,J.R.B.(2003) The meaning and measurement of destination image. Journal of Tourism Studies, 14 (1), pp.37-48.

Fyall, A., Wang,Y. and Garrod,B.(2012) Editorial of the Journal of Destination Marketing and Management 1, pp.1-3.

Garcia, B., R.and Cox,T. (2010) Creating an Impact: Liverpool's Experience as European Capital of Culture. http://www.liv.ac.uk/impacts08/Papers/Creating_an_Impact_web.pdf (Assessed 28/03/2010)

Glenn.A.J.Bowdin,J.Allen,I.W.O'Toole,R.Harris and I.McDonnell.(2011). Events Management. Third ed, Routledge. London and New York

Hawkins,H.(2013) Geography and art. An expanding field: site, the body and practice. Prog Hum Geogr 37(1): pp.52-71.

Jackson, L. (2008) "Residents' perceptions of the impacts of special event tourism", Journal of Place Management and Development, 1 (3), pp. 240-55.

Kotler, P., Armstrong, G., Wong, V. and Saunders,J. (2008) Principles of marketing. $5^{\text {th }}$ European ed. Prentice Hall

Madden, D. J. (2012) Cities Full of Symbols: A Theory of Urban Space and Culture. (P. J. M. Nas, Ed.). Leiden, NL: Leiden University Press. 
McCartney, G. and Osti, L. (2007) 'from cultural events to sports events: a case study of cultural authenticity in the Dragon Boat Races,' Journal of Sport \& Tourism, 12(1): 25-40.

Morgan, N., Pritchard, A., and Pride, R. (2011) Destination brands: Managing Place Reputation. Third ed, Elsevier.

Morrison, A. (2013) Marketing and Managing Tourism Destinations. New York: Routledge.

Munro,J.and Richards,B.(2011) Destination Brand Challenges: The digital challenge. In Wang, Y. and Pizam, A. Destination Marketing and Management, Theories and Applications. Oxfordshire: CAB International, pp.141-154.

Patton,M. (2015) Qualitative Research and Evaluation Methods: Integrating Theory and Practice. Fourth ed. Sage Publications. Thousand Oaks, CA.

Scott, A.J. (2010) Cultural economy and the creative field of the city, Geografiska Annaler: Series B, Human Geography 92 (2): pp 115-130.

Stepchenkova, S.,Kirilenko, A., Morrison, A.,( 2009) Facilitating Content Analysis in Tourism Research. Journal of Travel Research, 47(4), pp.454-469.

Thia, H., Ross, D., 2011. Using Content Analysis to Inquire into the Influence of Public Opinion on the Success of Public Private Partnerships. International Journal on GSTF Business Review, 1(1), pp.237-242.

Vitouladiti, O. (2014) Content Analysis as a Research Tool for Marketing, Management and Development Strategies in Tourism. Procedia Economics and Finance, El sevier, 9: pp. 278-287

Wagner,O., Peters, M.(2009) The Development and Communication of Destination Brand Identity- The Case of the Alps, in Tourism Destination Development and Branding, Proceedings, Eilat, Israel, October14-17,2-18

Williams, M. and Bowdin, G.A.J. (2007) Festival evaluation: An exploration of seven UK. Arts festivals, Managing Leisure, 12(2/3), pp.187-203.

http://www.ask-aladdin.com/Egypt-Travel-Tips/abu-simbel-sun_festival.html (Accessed 02/05/ 2017)

http://www.cdf.gov.eg/tobool/?q=ar/arabic-data-team/110 (Accessed 13/08/2017)

http://www.egyptindependent.com/number-tourists-coming-egypt-increased-march-apmas/Central Agency for Public Mobilization and Statistics (CAPMAS). 2017 (Accessed 14/06/2017)

http://www.intrepidtravel.com/us/egypt/egypt-experience-abu-simbel-sun-festival-101823 Accessed 02/09/2017)

http://www.egyptindependent.com/abu-simbel-temple-receives-620-tourists/ (Accessed 09/11/2017)

http://www.egyptindependent.com (Accessed 15/09/2017)

http://www.egypt.travel/attractions/sun-festival-at-abu-simbel-2/ETA Egyptian Tourism Authority (Accessed: 10/09/2017) 